\title{
Sistem Informasi Kepegawaian Berbasis Web pada PT. Indo Prima Jaya Palembang
}

\author{
Web Based Employment Information System
}

at PT. Indo Prima Jaya Palembang

\author{
Fajrin Shadiq A. F. ${ }^{1}$, M. Soleh ${ }^{2}$, Rizani Teguh ${ }^{3}$, Triana Elizabeth ${ }^{4}$ \\ ${ }^{1,2,3,4}$ Prodi Sistem Informasi, STMIK GI MDP, Palembang \\ email: ${ }^{1}$ fasja6@mhs.mdp.ac.id, ${ }^{2}$ muhammad.soleh@mhs.mdp.ac.id, ${ }^{3}$ rizani_teguh@mdp.ac.id, \\ ${ }^{4}$ trianaelizabeth@mdp.ac.id
}

\begin{abstract}
Abstrak
Tujuan penelitian ini adalah mempermudah dalam proses pengolahan kepegawaian dalam melakukan pendataan Karyawan, absensi, perhitungan gaji karyawan serta laporan untuk pimpinan dengan menggunakan website secara online pada PT. Indo Prima Jaya Palembang. Metodologi yang digunakan dalam penelitian ini adalah metodologi RUP (Rational Unified Process) sedangkan untuk pembuatan aplikasi website menggunakan bahasa pemrograman PHP, HTML, CSS, Javascript sedangkan server menggunakan XAMPP dan MySQL sebagai database. Hasil yang didapatkan adalah membangun sebuah sistem informasi Kepegawaian berbasis web yang dapat mengelola data kepegawaian.
\end{abstract}

Kata kunci : Sistem, Informasi, Kepegawaian, RUP, Website

\begin{abstract}
The purpose of this research is to facilitate the processing of personnel in conducting data collection employees, absenteeism, employee salary calculation and report to the leadership by using the website online at PT. Indo Prima Jaya Palembang. The methodology used in this research is the methodology RUP (Rational Unified Process) while for the manufacture of web applications using the programming language PHP, HTML, CSS, Javascript and server using $X A M P P$ and MYSQL as the database. The results obtained are building a web-based information systems Personnel who can manage personnel data.
\end{abstract}

Keywords : System, Information, Personnel, RUP, Website

\section{PENDAHULUAN}

Seiring perkembangan teknologi informasi yang pesat saat ini, teknologi informasi memiliki peranan sangat penting dalam suatu organisasi, suatu organisasi sulit untuk berkembang tanpa teknologi informasi karena teknologi informasi merupakan sebuah fasilitas penunjang kesuksesan dari suatu organisasi. Setiap perusahaan pasti memiliki pegawai, apalagi pegawai dalam suatu perusahaan sangat banyak, sehingga mendorong perusahaan agar memiliki sistem kepegawaian yang terintegrasi dan terpusat. Saat ini PT. Indo Prima Jaya Palembang khususnya dibagian kepegawaian belum sepenuhnya maksimal penggunaan sistem kepegawaian karena hanya menggunakan aplikasi kantor biasa yaitu menggunakan Microsoft Excel maupun Word yang memiliki kelemahan dalam proses penginputan data karena memerlukan masih waktu yang cukup lama.

Adapun permasalahan yang ada pada PT IPJ ini yaitu data gaji belum terintegrasi dengan data pegawai dan absen sehingga terjadi perubahan data relatif lama. dikarenakan absensi bersifat manual yang masih bisa disalahgunakan dan belum akurat, akibatnya sering terjadi kesalahan 
perhitungan gaji. Dari permasalahan tersebut penulis akan memberikan solusi yaitu membangun sebuah sistem informasi kepegawaian dengan menggunakan bahasa pemrograman PHP, HTML, CSS, javascript. Sedangkan fitur yang akan dibuat mencakup pengelolaan data pegawai, jabatan, cabang, lowongan, pelamar, absen, pengunduran diri, perhitungan gaji, laporan data absen, laporan gaji, laporan pegawai. Penulis menggunakan metodologi pengembangan RUP, analisis permasalahan dengan PIECES, analisis kebutuhan Use Case Diagram, perancangan menggunakan UML.

Penelitian yang pernah dilakukan oleh Rahmat Gunawan, Erny Chandra dengan judul Sistem Informasi Pengelolaan Data Kepegawaian Pada Pada PT. Sigap Panca Berbasis Web dan Iterasi. Permasalahan yaitu dibagian kepegawaian mengalami kesulitan dalam mendapatkan informasi pegawai yang sedang bertugas, informasi data karyawan, informasi tentang pelaksanaan kegiatan pekerjaan, data pelanggan maupun pendataan absensi, dan masih sulit menentukan gaji karyawan dikarenakan perhitungan penggajiannya berdasarkan buku arsip absensi yang telah direkap terlebih dahulu.. Beberapa fitur yang akan dibangun yaitu data pegawai, penggajian, data pelanggan, data kontrak, data absensi, pengaturan absensi, data analisis absensi,data analisis $\operatorname{kontrak[3].~}$

Penelitian yang pernah dilakukan oleh Lidya Anjaya dan Roni Lukito dengan judul Sistem Informasi Manajemen Kepegawaian Berbasis Web Pada PT. Bintang Baru Sejati Palembang. Penelitian ini untuk membantu memudahkan dalam pengelolaan kepegawaian pada manager puncak, sehingga dapat membantu pimpinan dalam mengetahui kinerja masing - masing pegawai, serta memberikan informasi manajerial yang dapat membantu pimpinan dalam pengambilan keputusan[2].

Penelitian yang pernah dilakukan oleh Mirza dan Desi Prihartini berjudul sistem informasi kepegawaian berbasis web pada PT. Bukut Mayana Palembang. Sistem ini dapat mempermudah pihak HRD dalam penerimaan rekrutmen karyawan dengan menggunakan internet. Serta dapat mempermudah HRD dalam mengelolah data kepegawaian seperti data mutasi pegawai, data penggajian, dan laporan bulanan[4].

Sistem informasi kepegawaian adalah sistem informasi manajemen yang bermanfaat untuk mengolah data, mengumpulkan data, menyediakan akses data dan informasi sebagai pendukung pengambilan keputusan untuk meningkatkan kinerja organisasi khususnya di bidang kepegawaian.

Use Case Diagram adalah diagram yang menggambarkan interaksi pengguna antar sistem dengan sistem lainnya. Dengan kata lain menggambarkan orang yang akan menggunakan sistem dan dengan cara apa pengguna mengharapkan untuk berinteraksi dengan sistem.

\section{METODE PENELITIAN}

Dalam melakukan penelitian ini, metodologi yang digunakan yaitu metodologi RUP (Rational Unified Process). Metodologi RUP adalah pendekatan pengembangan perangkat lunak fokus pada arsitektur (architecture-centric) yang dilakukan berulang- ulang (iterative) lebih ditekankan kearah penggunaan kasus (use case driven). Metode RUP memiliki fase pengembangan, sebagai berikut:

1. Inception (Permulaan)

Tahap ini mendefinisikan kebutuhan akan sistem yang akan dibuat (requirement) dan pemodelan proses bisnis yang dibutuhkan (business modeling)

2. Elaboration (Perluasan/perencanaan)

Tahap ini fokus pada Prototype perencanaan arsitektur sistem yang memungkinkan mendeteksi resiko yang akan terjadi dari arsitektur yang dibuat pada tahap analisis dan desain sistem.

3. Construction (Konstruksi)

Tahap ini lebih pada pengujian dan penerapan sistem yang fokus pada implementasi perangkat lunak pada kode program dari pengembangan komponen dan fitur - fitur sistem yang dibuat sehingga menghasilkan produk perangkat lunak dimana menjadi syarat dari 
batas/tonggak kemampuan operational awal.

4. Transition (Transisi)

Tahap ini lebih fokus pada instalasi atau deployment sistem agar dapat dipahami oleh user. Tahap ini menghasilkan produk perangkat lunak dimana menjadi syarat dari batas/tonggak kemampuan operational awal. Aktifitas pada tahap ini termasuk pada pelatihan user, pemeliharaan dan pengujian sistem apakan sistem sudah memenuhi harapan user

\section{HASIL DAN PEMBAHASAN}

\subsection{Gambaran Umum Perusahan}

PT. Indo Prima Jaya memiliki 5 cabang diantaranya Jambi, Lampung, Bogor, Cikarang, Tangerang. Jumlah seluruh pegawai pada PT. Indo Prima jaya ekitar 160 orang yang tersebar di semua kantor cabang. Berikut ini adalah gambar struktur Organisasi pada PT. Indo Prima Jaya Pusat di Palembang.

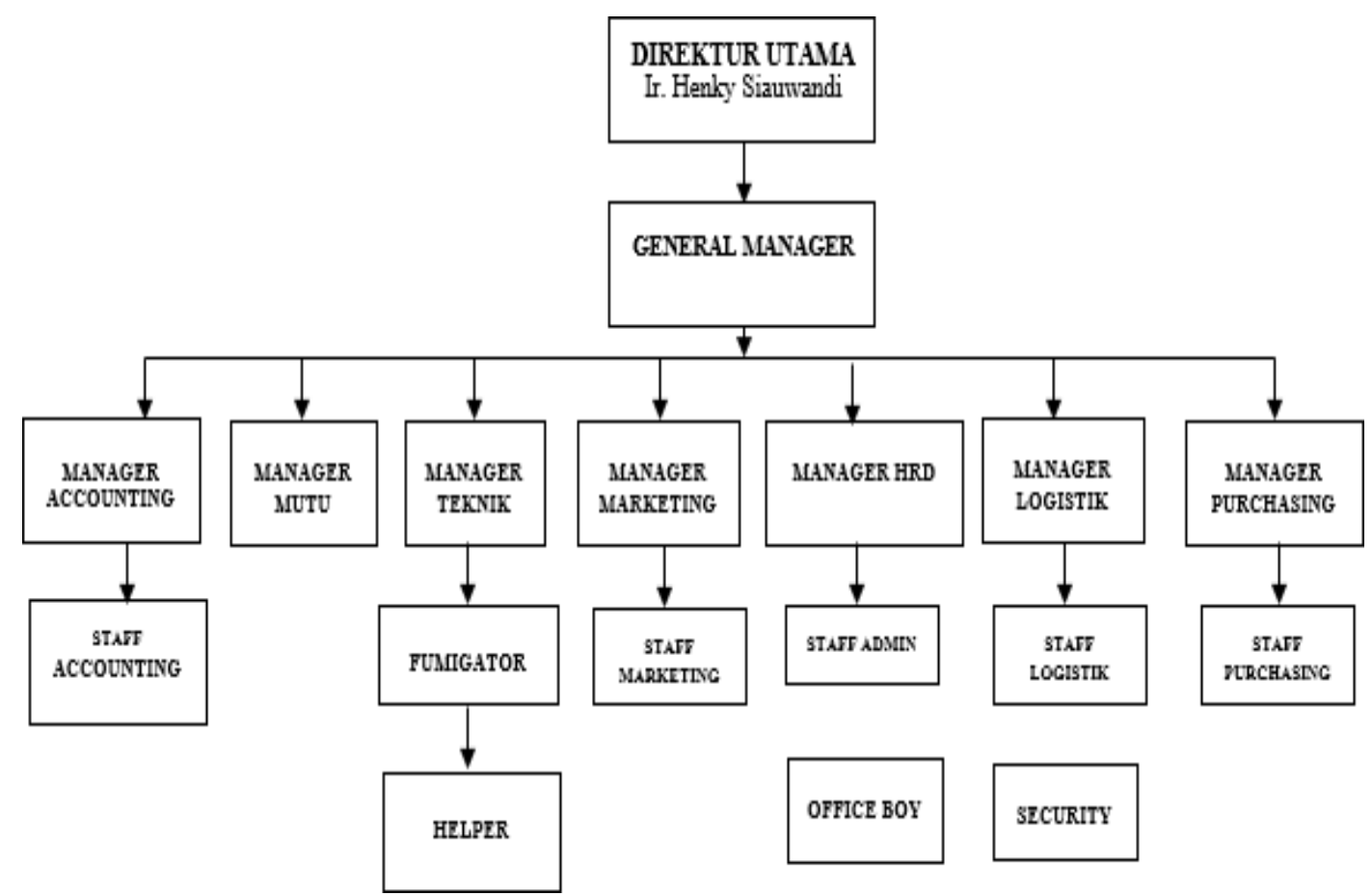

Sumber: PT. Indo Prima Jaya

Gambar 1 Struktur Organisasi Pusat

\subsection{Analisis Permasalahan}

Dalam menentukan permasalahan penulis menggunakan analisis PIECES, seperti yang ada dibawah ini :

\section{Performance}

Ketidak efisienan waktu untuk merekap data absensi dan data gaji pegawai.

\section{Information}

Data tidak aman dari kecelakaan atau penyalahgunaan data untuk kepentingan sendiri.

\section{Economics}

Pengeluaran untuk gaji pegawai tidak sesuai akibat dari kesalahan human error.

\section{Control}

Manipulasi atau kecurangan dalam proses absensi karena absensi masih manual.

\section{Efficiency}


Membutuhkan waktu yang lama untuk merekap gaji pegawai.

6. Services

Sistem yang berjalan tidak menghasilkan informasi yang lengkap.

\subsection{Prosedur Sistem Berjalan}

Terdapat beberapa prosedur pada sistem yang telah berjalan pada PT. Indo Prima Jaya Palembang. Berikut gambar prosedur dalam pengolahan pendataan pegawai, pendataan absensi, perhitungan data gaji pegawai dan pengajuan mutasi.

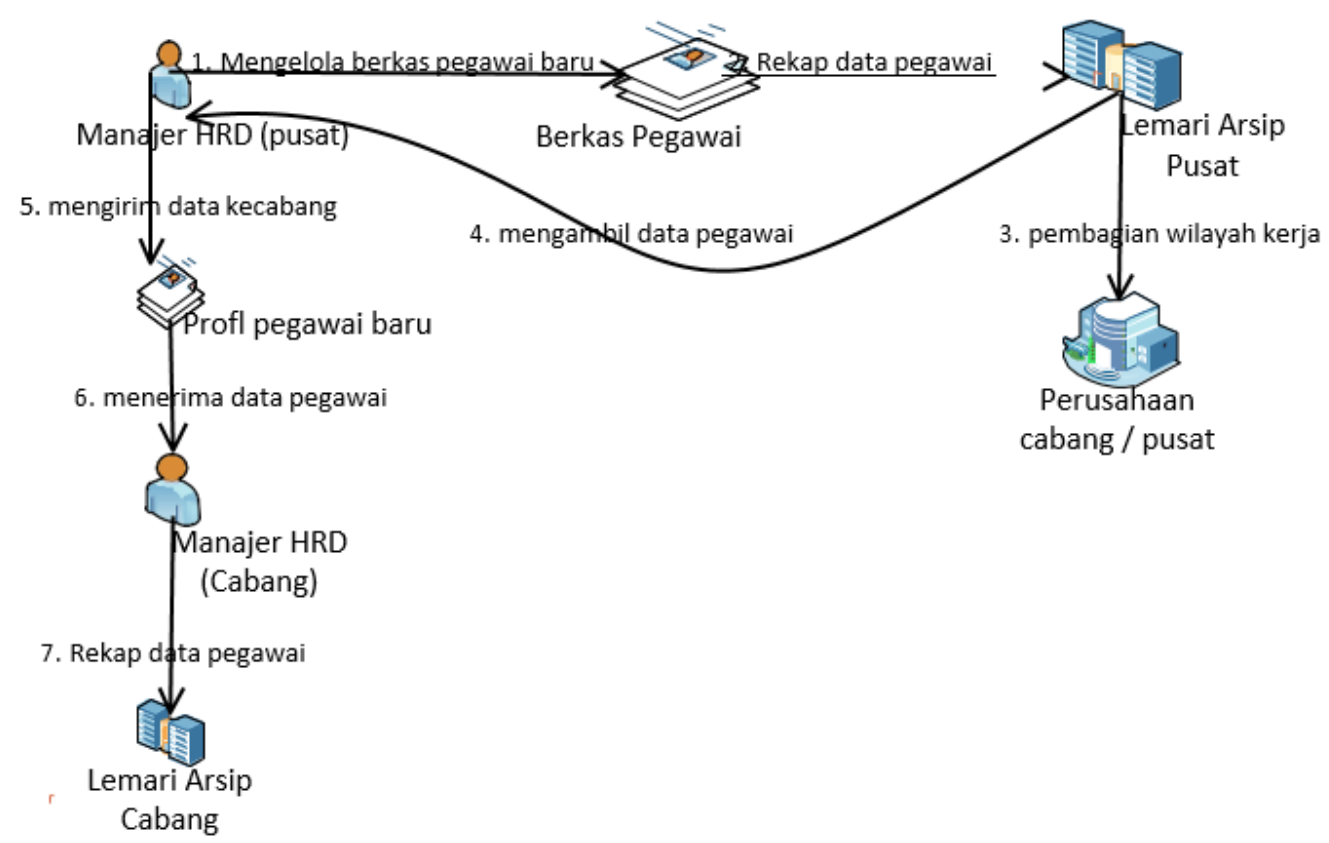

Gambar 2 Rich Picture Pengolahan Data Pegawai Baru Pusat 


\subsection{Analisis Kebutuhan}

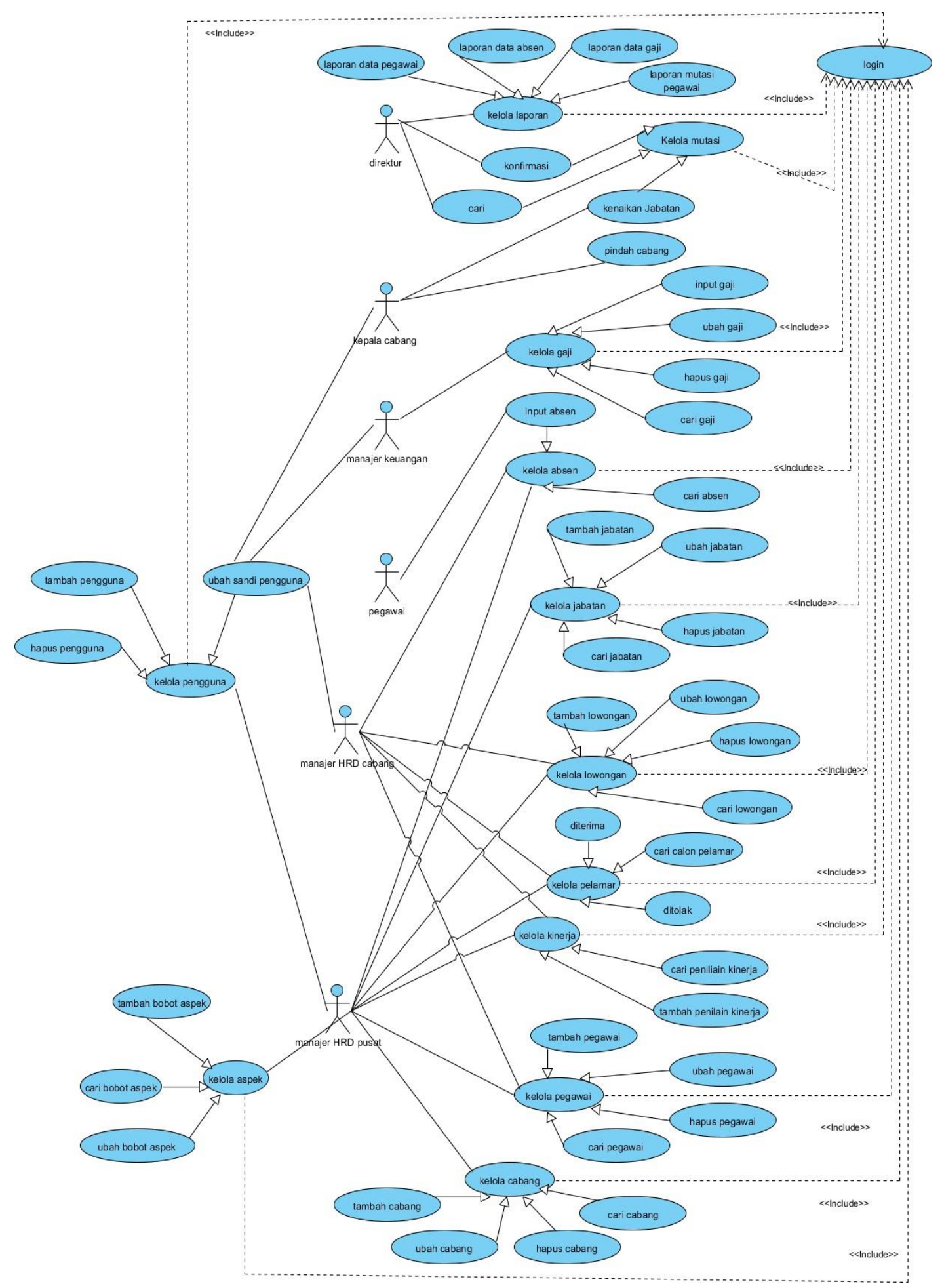

Gambar 3 Use Case Diagram

\subsection{Rancangan Sistem}

\subsubsection{Activity Diagram}

Activity Diagram menggambarkan proses bisnis dan urutan aktivitas dalam sebuah proses, yang biasanya dipakai pada business modeling untuk memperlihatkan urutan 
aktivitas bisnis. Selain bisnis, activity diagram juga dapat digunakan menggambarkan logical procedural sistem, dan aliran kerja kasus lainnya. Pembuatan activity diagram diharapkan dapat bermanfaat untuk membantu menggambarkan proses secara keseluruhan.

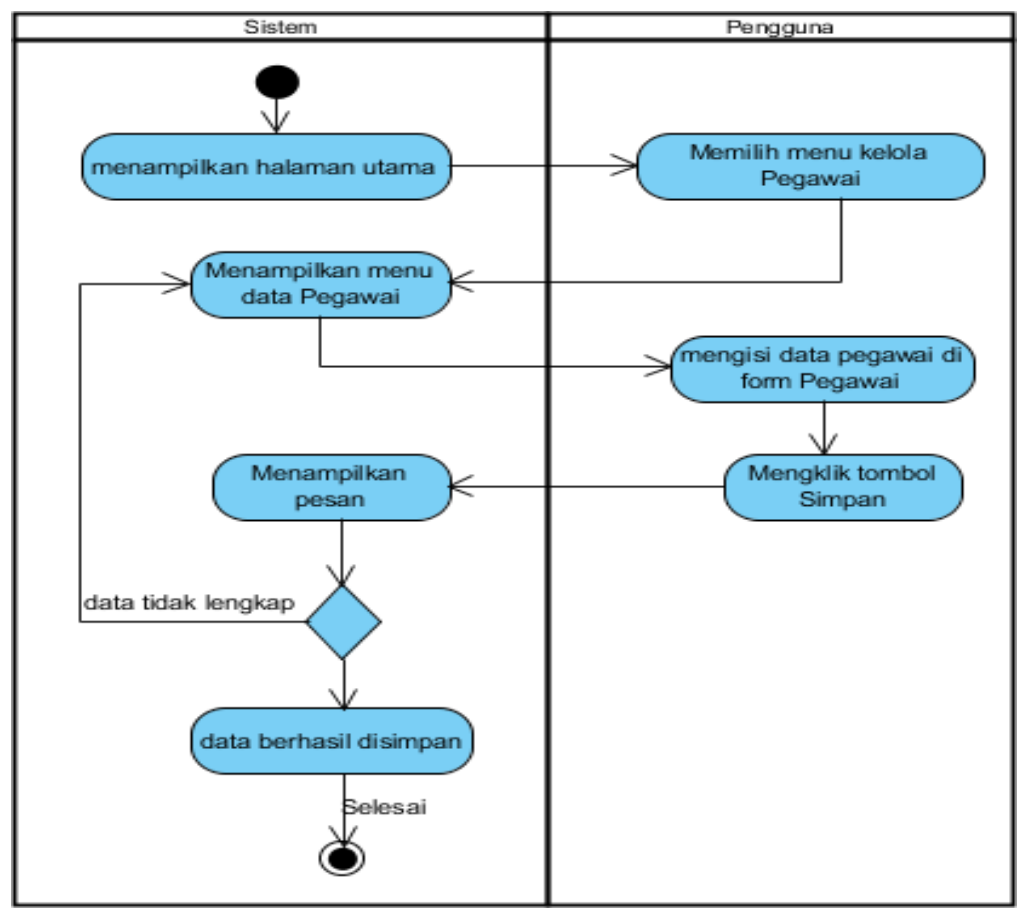

Gambar 4 Activity Diagram Tambah Data Pegawai

\subsubsection{Squence Diagram}

Sequence diagram adalah suatu diagram yang menggambarkan interaksi antar proyek dan mengindikasikan komunikasi diantara objek-objek tersebut. Diagram ini juga menunjukkan serangkaian pesan yang diperuntukkan oleh objek-objek untuk melakukan suatu aksi tertentu. Sequence diagram ini terdiri dari dimensi vertikal (waktu) dan dimensi horizontal (objek-objek yang terkait).

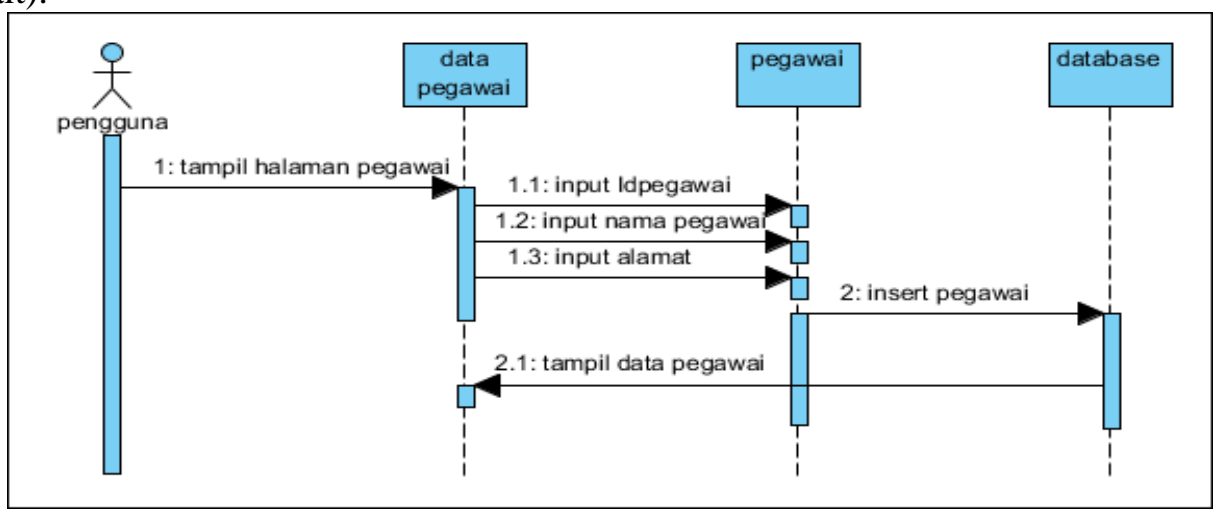

Gambar 5 Sequnce Diagram Tambah Data Pegawai

\subsubsection{Class Diagram}

Class diagram merupakan diagram yang menggambarkan jenis - jenis objek dalam sistem dengan berbagai macam relasi yang dimiliki. Class diagram juga merupakan diagram yang paling umum dijumpai pada pemodelan berbasis UML 


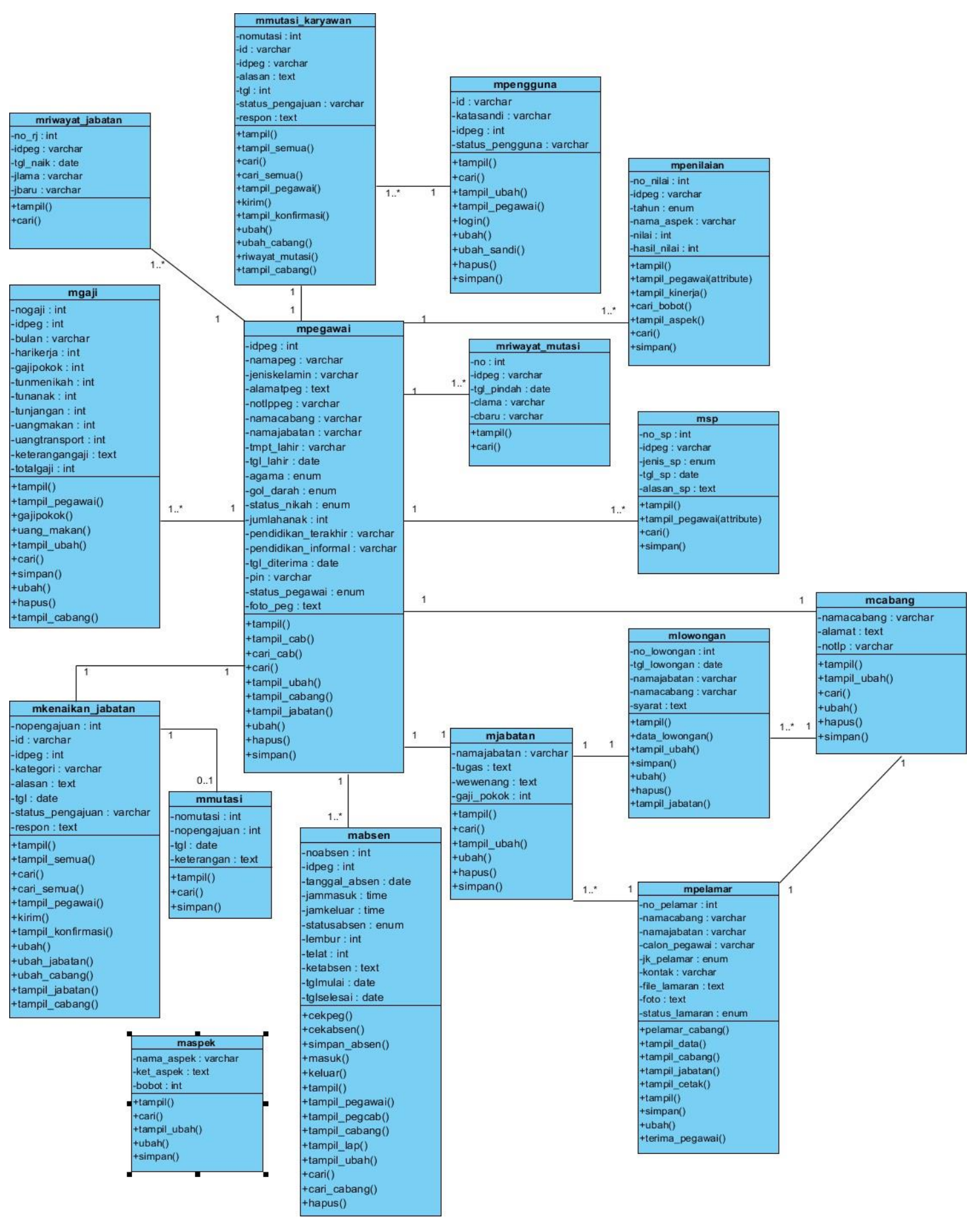

Gambar 6 Class Diagram

\subsection{Tampilan Antarmuka}

3.6.1 Tampilan Depan

Halaman depan ini adalah tampilan awal pengguna ketika akan login. Selain login pengguna juga dapat melihat lowongan kerja yang ada pada menu lowongan sebelah login. 

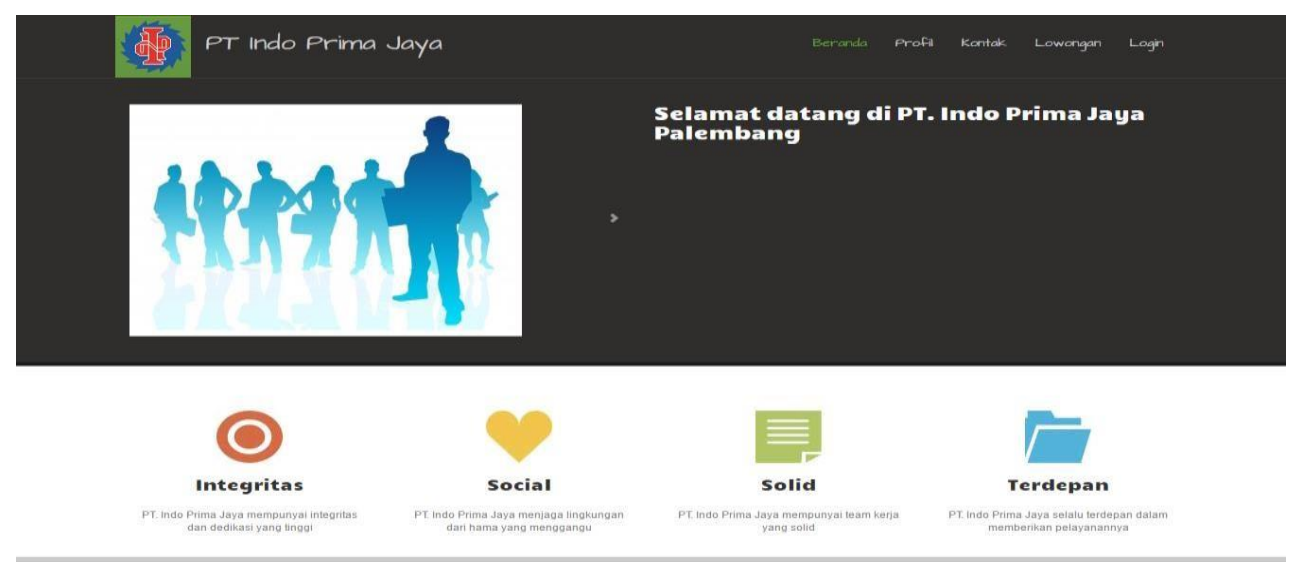

Gambar 7 Tampilan Depan

\subsubsection{Tampian Login}

Tampilan ini merupakan tampilan login berisi ID dan Kata sandi yang akan diinput oleh user untuk masuk ke dalam aplikasi

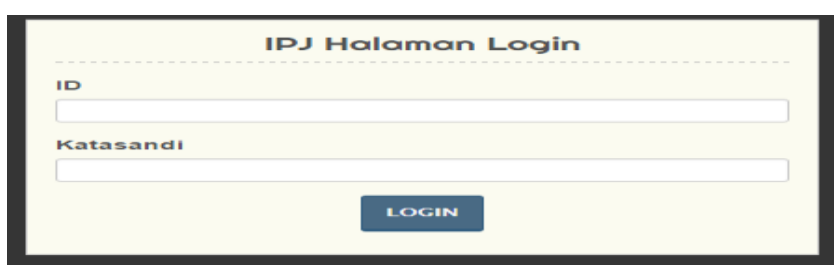

Gambar 8 Tampilan Login

\subsubsection{Tampilan Beranda HRD Pusat}

Tampilan dibawah ini merupakan tampilan beranda hrd pusat, berisi menu-menu data pegawai pusat.

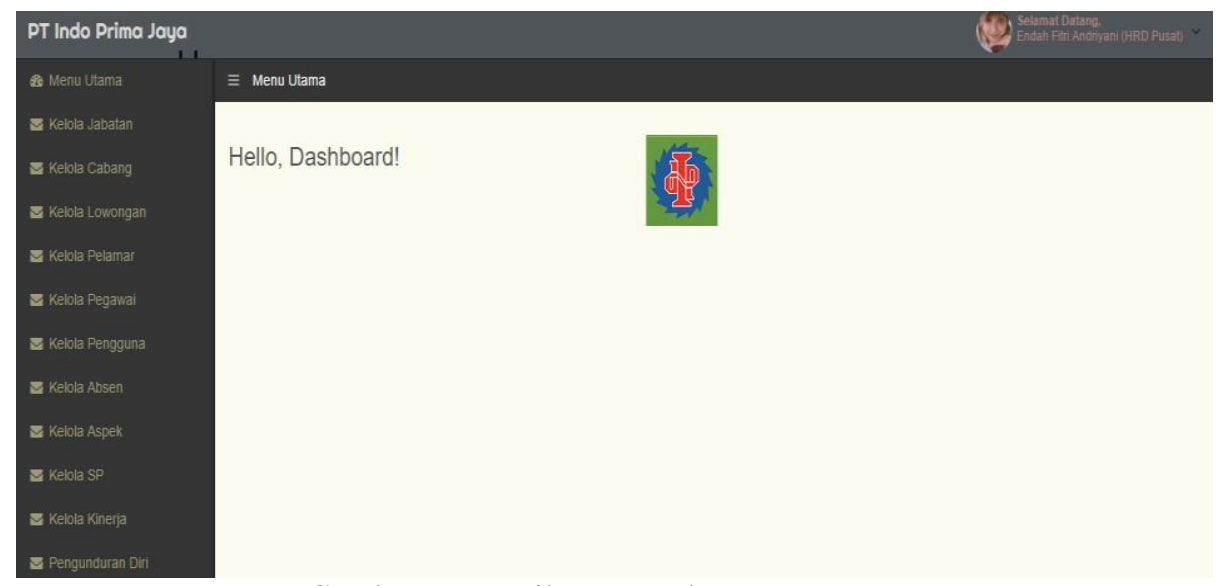

Gambar 9 Tampilan Beranda HRD Pusat

\subsubsection{Tampilan form Gaji}

Tampilan dibawah ini adalah tampilan dari form gaji sebuah halaman yang berfungsi untuk proses perhitungan gaji yang dilakukan oleh manajer keuangan.. 


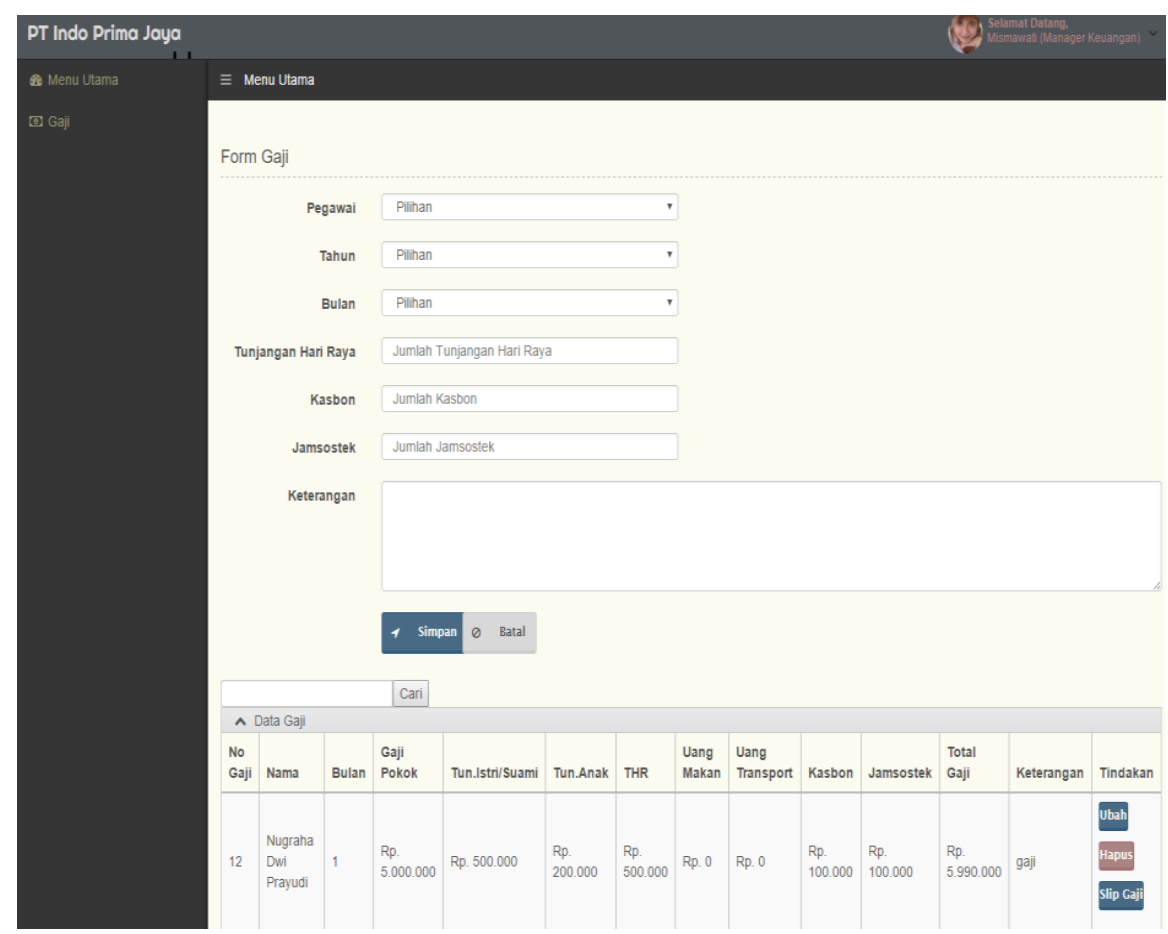

Gambar 10 Tampilan Form Gaji

\subsubsection{Tampilan Laporan Data Gaji}

Tampilan dibawah ini adalah laporan data gaji sebuah halaman yang berfungsi menampilkan laporan data gaji pegawai

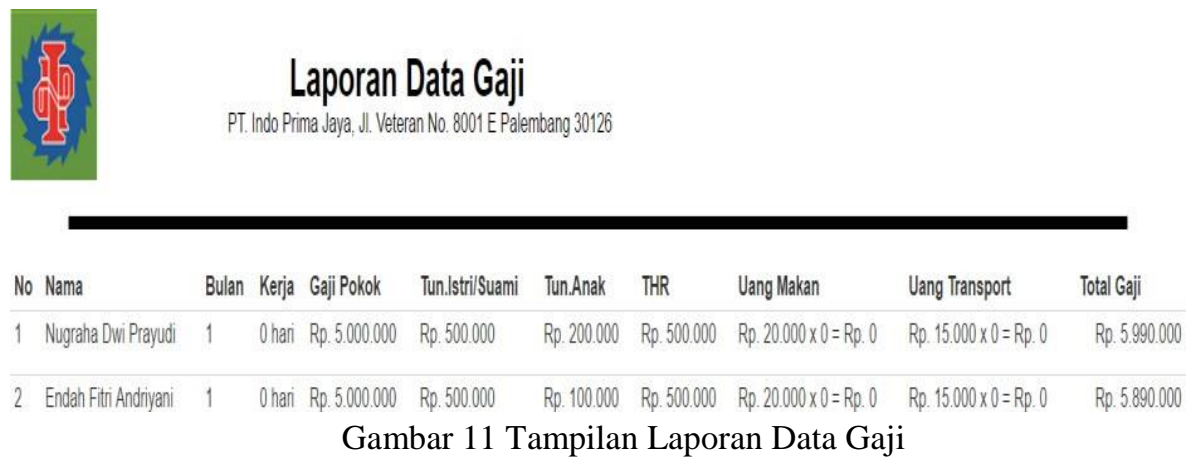

\subsubsection{Tampilan Slip Gaji}

Dibawah ini merupakan tampilan dari slip gaji yang telah dilakukan proses penggajian yang telah diinput oleh manager keuangan. 


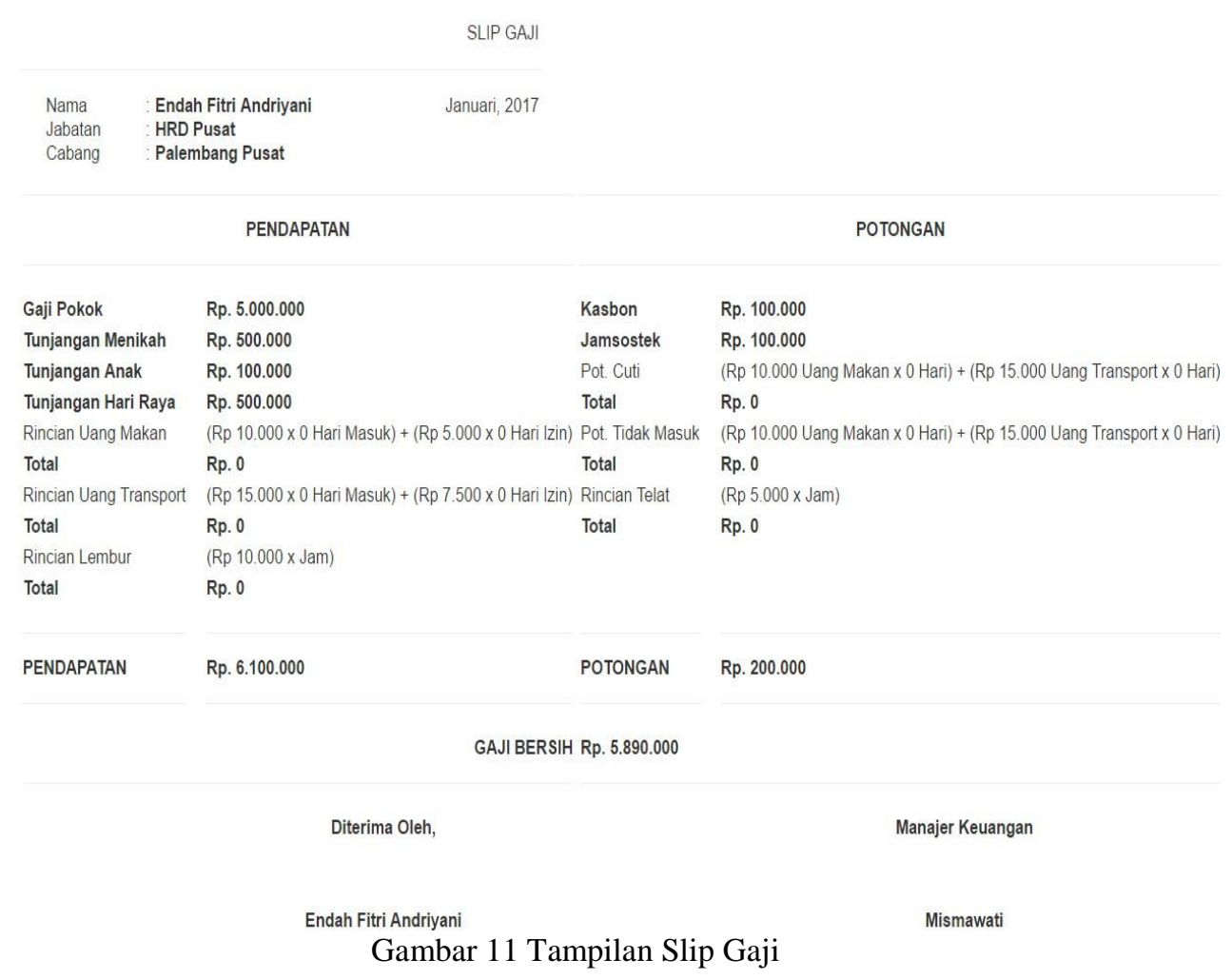

\section{KESIMPULAN DAN SARAN}

\subsection{Kesimpulan}

Berdasarkan hasil laporan yang telah diuraikan dalam laporan ini, maka penulis dapat menarik beberapa kesimpulan yaitu:

1. Sistem Informasi Kepegawaian Berbasis Web pada PT. Indo Prima Jaya ini dapat memudahkan pihak manajemen dalam proses pengolahan pendataan karyawan, pendataan absensi, perhitungan data gaji karyawan, beserta laporan untuk pimpinan.

2. Sistem Informasi Kepegawaian Berbasis Web pada PT. Indo Prima Jaya ini dapat mempercepat dalam pencarian data pegawai dan pembuatan laporan.

3. Dapat mempermudah dan mempercepat dalam memberikan informasi penerimaan calon pegawai baru pada PT. Indo Prima jaya.

4. Sistem Informasi Kepegawaian Berbasis Web pada PT. Indo Prima jaya ini dapat mengatasi kesalahan dalam perhitungan gaji.

\subsection{Saran}

Berdasarkan kesimpulan yang telah diuraikan, maka penulis ingin memberikan beberapa saran untuk membantu dalam pengembangan sistem informasi kepegawaian berbasis web pada PT. Indo Prima Jaya Palembang agar kedepannya web ini dapat menjadi yang lebih baik lagi. Adapun saran yang penlisan ajukan yaitu:

1. Sistem informasi kepegawaian berbasis web pada PT. Indo Prima jaya Palembang ini dapat dikembangkan lagi baik dalam desain tampilannya dan juga dari segi fungsionalnya.

2. Perlu dilakukannya back-up data - data kepegawaian secara berkala baik perminggu maupun perbulan supaya dapat menghindari terjadinya kehilangan atau kerusakan data. 


\section{DAFTAR PUSTAKA}

[1] A.S, Rossa dan Shalahudin M 2013, Rekayasa Perangkat Lunak Terstruktur dan Berorientasi Objek, Informatika, Bandung

[2] Anjaya, Lidya and Lukito, Roni, 2013, Sistem Informasi Manajemen Kepegawaian Berbasis Web pada PT Bintang Baru Sejati Palembang. STMIK MDP dari http://eprints.mdp.ac.id/830/.22

[3] Gunawan, Rahmat and Chandra, Erny, 2013, Sistem Informasi Pengelolaan Data Kepegawaian Pada Pt. Sigap Panca Marga. STMIK MDP dari http://eprints.mdp.ac.id/811/.

[4] Mirza, Mirza and Prihartini, Desi and Sopriyadi, Hendri, 2014, Sistem Informasi Kepegawaian Berbasis Web Pada PT. Bukut Mayana Palembang. STMIK MDP dari http://eprints.mdp.ac.id/1032/.

[5] Wicaksono, Agung 2011, Manual SIMPEG. http://fp.ub.ac.id/kepegawaian/wpcontent/uploads/2012/06/SIMPEG-User-Guide-v.1.1.docx . Diakses pada tanggal 10 September 2016 